\title{
Wire-guided endoscopic snare resection of a choledochocele-associated villous adenoma
}

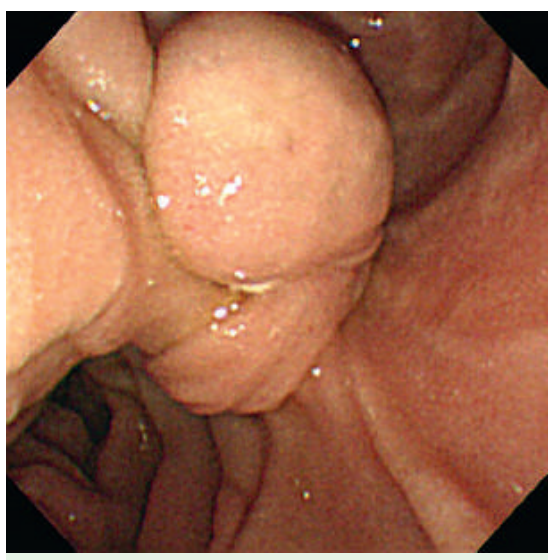

Fig. 1 Endoscopic view of the choledochocele.

Adenomas arising in a choledochocele are usually resected surgically because they are difficult to completely remove endoscopically and they are associated with a high malignancy potential [1-2]. We successfully performed an endoscopic snare resection for choledochocele-associated villous adenoma with high-grade dysplasia.
A 76-year-old woman was admitted complaining of epigastric pain lasting for several days. Duodenoscopy revealed a soft cystic-mass-like lesion covered with normal mucosa above the ampulla of Vater (๑ Fig. 1).

Intraductal ultrasound showed an anechogenic cystic mass with diffuse wall thickening and preserved wall layer (๑ Fig. 2).

Magnetic resonance cholangiopancreatography showed an oval-shaped cystic mass above the ampulla of Vater. A major endoscopic sphincterotomy was conducted. Following sphincterotomy, duodenoscopy revealed mucosal nodules on the in ner surface of the choledochocele (๑ Fig. 3).

Histopathologic findings of the biopsy specimen showed an adenoma with high-grade dysplasia ( $\bullet$ Fig. 4).

Because the patient wanted to undergo an endoscopic treatment, we performed a wire-guided endoscopic snare resection for the choledochocele with the adenoma (๑ Fig. 5, Video 1).

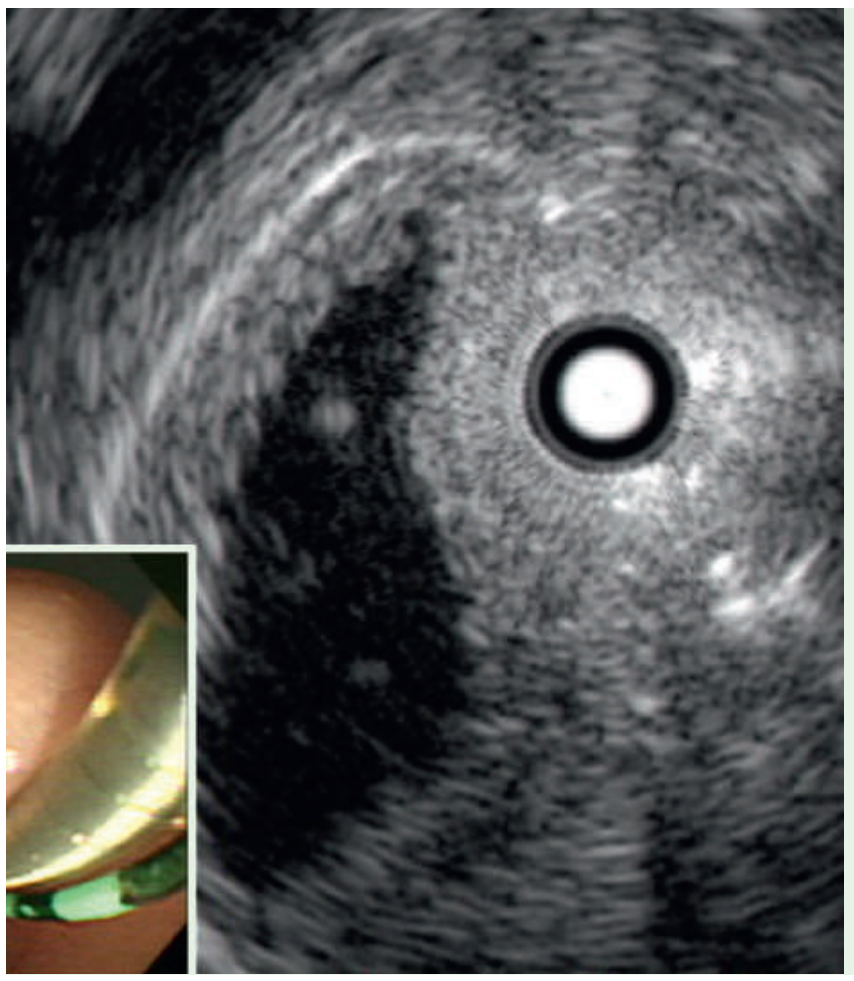

Fig. 2 Intraductal ultrasound showing an anechogenic cystic mass with diffuse wall thickening.

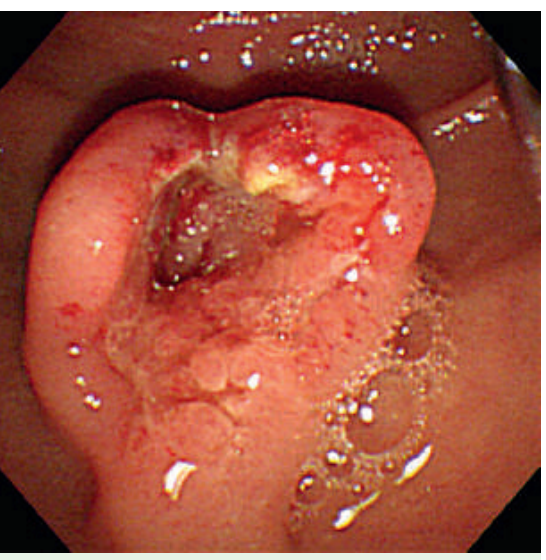

Fig. 3 Endoscopic view after a major endoscopic sphincterotomy.

During the 1-year follow-up duodenoscopy, no remnant or recurrence of the adenoma was found.

The surgical approach may be too invasive for a choledochocele with adenoma. Itoi et al. [3] performed a balloon-catheter-assisted endoscopic snare resection using a double-channel duodenoscope for choledochocele. We attempted to perform a wire-guided endoscopic snare resection using the previously reported method for adenomas of the major papilla [4]. En bloc resection was successfully achieved without any procedure-related complications or residual tumor. In conclusion, endoscopic snare resection may be a feasible and effective solution for selected patients with choledochocele associated with a villous adenoma.

Endoscopy_UCTN_Code_CCL_1AZ_2AK Endoscopy_UCTN_Code_TTT_1AR_2AK

\section{Video 1}

Wire-guided endoscopic snare resection. The guide wire was inserted into the main pancreatic duct. An electrosurgical snare was then inserted along the guide wire. The snare was manipulated to grasp the base of the choledochocele before en bloc resection was conducted. After the excision had been completed, a pancreatic stent was immediately placed along the indwelling guide wire. Histopathologic examination of the resected specimen showed a villous adenoma with a clear resection margin ( $\bullet$ Fig. 6 ). 


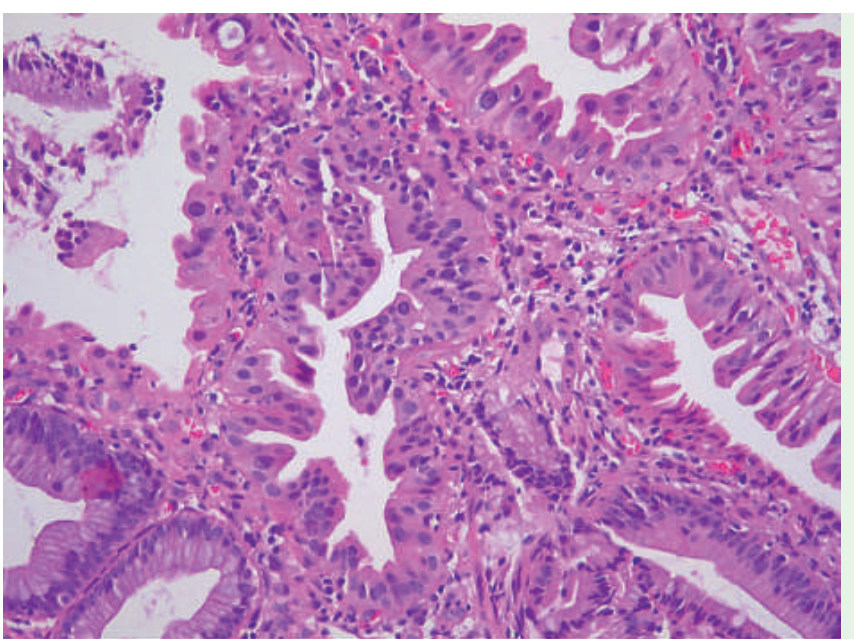

Fig. 4 Histopathologic findings of the biopsy specimen (hematoxylin and eosin stain, $\times 200$ )

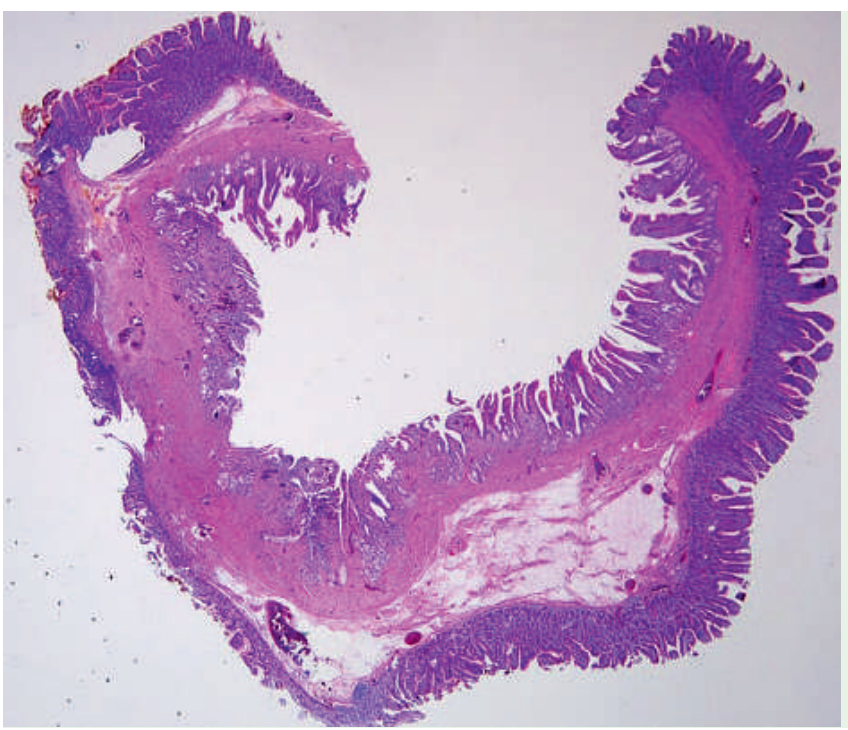

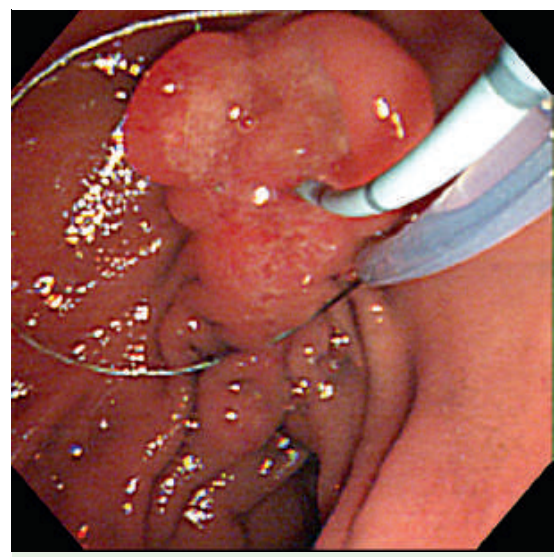

Fig. 5 Endoscopic view for the wire-guided endoscopic snare resection.

Bibliography

DOI $10.1055 / \mathrm{s}-0029-1214429$

Endoscopy 2009; 41: E78-E79

(c) Georg Thieme Verlag KG Stuttgart · New York . ISSN 0013-726X scopic resected specimen showing villous adenoma (hematoxylin and eosin stain, $\times 10$ ).

J. K. Park ${ }^{1}$, J. H. Moon ${ }^{1}$, H. K. Kim¹, H. J. Choi ${ }^{1}$, J. H. Kang ${ }^{1}$, H. K. Kim², B. M. Ko ${ }^{1}$, Y. D. Cho ${ }^{1}$, M. S. Lee ${ }^{1}$, C. S. Shim ${ }^{1}$

1 Digestive Disease Center, Department of Internal Medicine, Soon Chun Hyang University School of Medicine, Bucheon and Seoul, Korea

2 Department of Pathology, Soon Chun Hyang University School of Medicine, Bucheon, Korea

\section{References}

1 Kawakami H, Kuwatani M, Onodera $M$ et al. Villous adenoma arising in choledochocele. Gastrointest Endosc 2007; 66: 1231 - 1232

2 Ohtsuka T, Inoue K, Ohuchida J et al. Carcinoma arising in choledochocele. Endoscopy 2001; 33: 614-619

3 Itoi T, Gotoda T, Yasuda I et al. Balloon-catheter-assisted complete endoscopic snare resection for choledochocele by using doublechannel duodenoscope (with videos). Gastrointest Endosc 2007; 66: 622 - 625

4 Moon JH, Cha SW, Cho YD et al. Wire-guided endoscopic snare papillectomy for tumors of the major duodenal papilla. Gastrointest Endosc 2005; 61: 461 - 466

\section{Corresponding author}

\section{J. H. Moon, MD, PhD}

Soon Chun Hyang University School of Medicine Digestive Disease Center

Soon Chun Hyang University Bucheon Hospital 1174 Jung-Dong

Wonmi-Ku

Bucheon 420-767

Korea

Fax: +82-32-6215080

jhmoon@schbc.ac.kr 